\title{
The Continuum of Acute Kidney Injury and Chronic Kidney Disease in Children
}

\author{
Lavjay Butani* \\ Chief Pediatric Nephrology, University of California, Davis, 2516, Stockton Blvd., Sacramento, CA, USA
}

"Corresponding author: Lavjay Butani, Professor of Pediatrics, Chief Pediatric Nephrology, University of California, Davis, 2516, Stockton Blvd., Room 348, Sacramento, CA 95817, USA, Tel: 916-734-8118; Fax: 916-734-0629; E-mail: 1butani@ucdavis.edu

Received Date: February 12, 2018; Accepted Date: February 14, 2018; Published Date: February 21, 2018

Copyright: (c) 2018 Butani L. This is an open-access article distributed under the terms of the Creative Commons Attribution License, which permits unrestricted use, distribution, and reproduction in any medium, provided the original author and source are credited.

Citation: Butani L (2018) The Continuum of Acute Kidney Injury and Chronic Kidney Disease in Children. J Nephrol Ther 8: e118. doi: 10.4172/2161-0959.1000e118

\section{Editorial}

Acute kidney injury (AKI), the sudden deterioration in renal function, is common in hospitalized children, and is associated, in a graded manner, with longer hospital stays and poorer short-term outcomes [1]. While AKI was previously perceived as being a selflimited problem in those who survived, a growing body of recent literature suggests otherwise; whether this is related, at least in part, to the changing epidemiology of pediatric AKI [2], remains to be clarified. One of the earliest studies to suggest this was a meta-analysis of outcomes data in children with diarrheal hemolytic uremic syndrome, a common cause of AKI in hospitalized children [3]; this study showed that a large percentage of children (25\%) developed long term sequelae and progressed to develop chronic kidney disease (CKD), with manifestations such as a subnormal GFR, hypertension or proteinuria. Subsequent studies from a more heterogenous patient population with AKI [4-6] have confirmed the lingering sequeae of AKI, even of mild to moderate severity, on the kidney. The incidence of CKD is even higher in pediatric survivors of nephrotoxic AKI, albeit in a very high-risk and predominantly post-transplant patient population [7] which certainly may have played a contributory role. All of these studies indicate the need for children with AKI to be followed closely after discharge and monitored for signs of CKD and also for the future development of CKD in a longitudinal manner; ideally this should be done by a pediatric nephrology team or in conjunction with such a team. The longitudinal nature of follow up cannot be over emphasized since CKD may develop after a long symptom free period, as a consequence of hyperfiltration injury [8,9]. While being aware of the risk of development and progression of CKD in such patients may help protect these patients from additional nephrotoxic insults and enable providers to even more persuasively counsel patients on maintaining a healthy lifestyle, some patients will inevitably develop progressive CKD to the point of needing renal replacement therapy. Accurately predicting the time course for such a sub group of patients has been challenging, limiting the ability to plan their care in a deliberate and thoughtful manner. A recent study from the Chronic Kidney Disease in Children (CKiD) cohort provides data that bring us one step closer to this goal [10]. For this particular analysis, data on 603 children with a GFR of less than $60 \mathrm{ml} / \mathrm{min} / 1.73 \mathrm{~m}^{2}$ were analyzed; $144(23.9 \%)$ of these children developed end stage renal disease (ESRD) within 5 years of enrollment. A kidney failure risk equation (KFRE) based on 4 variables (age, sex, bedside Schwartz estimated glomerular filtration rate, and ratio of albumin to creatinine levels) and 8 variables (4 variables plus serum calcium, phosphate, bicarbonate, and albumin levels) was evaluated as a predictor of development of ESRD. Both risk equations provided excellent discrimination of the risk of ESRD and therefore add to the existing toolbox that we now have in helping care for children with CKD and their families. How precisely the data from this study can be used to inform and modify care, remain to be clearly elucidated; nevertheless, this is a great first step in helping further improve care of this highly vulnerable population.

\section{References}

1. Sutherland SM, Byrnes JJ, Kothari M, Longhurst CA, Dutta S, et al. (2015) AKI in hospitalized children: comparing the pRIFLE, AKIN, and KDIGO definitions. Clin J Am Soc Nephrol 10: 554-556.

2. Hui-Stickle S, Brewer ED, Goldstein SL (2005) Pediatric ARF epidemiology at a tertiary care center from 1999 to 2001. Am J Kidney Dis 45: 96-101.

3. Garg AX, Suri RS, Barrowman N, Rehman F, Matsell D, et al. (2003) Longterm renal prognosis of diarrhea-associated hemolytic uremic syndrome: a systematic review, meta-analysis, and meta-regression. JAMA 290: 1360-1370.

4. Mammen C, Al Abbas A, Skippen P, Nadel H, Levine D, et al. (2012) Longterm risk of CKD in children surviving episodes of acute kidney injury in the intensive care unit: a prospective cohort study. Am J Kidney Dis 59: 523-530.

5. Viaud M, Llanas B, Harambat J (2012) Renal outcome in long-term survivors from severe acute kidney injury in childhood. Pediatr Nephrol 27: 151-152.

6. Askenazi DJ, Feig DI, Graham NM, Hui-Stickle S, Goldstein SL (2006) 3-5 Year longitudinal follow-up of pediatric patients after acute renal failure. Kidney Int 69: 184-189.

7. Menon S, Kirkendall ES, Nguyen H, Goldstein SL (2014) Acute kidney injury associated with high nephrotoxic medication exposure leads to chronic kidney disease after 6 months. J Pediatr 165: 522-527.

8. Butani L, Morgenstern BZ (2007) Long-term outcome in children after Henoch-Schonlein purpura nephritis. Clin Pediatr (Phila) 46: 505-511.

9. Goldstein AR, White RH, Akuse R, Chantler C (1992) Long-term follow-up of childhood Henoch-Schonlein nephritis. Lancet 339: 280-282.

10. Winnicki E, McCulloch CE, Mitsnefes MM, Furth SL, Warady BA, et al. (2018) Use of the Kidney Failure Risk Equation to Determine the Risk of Progression to End-stage Renal Disease in Children With Chronic Kidney Disease. JAMA Pediatr 172: 174-180. 